\title{
MET aberrations and c-MET inhibitors in patients with gastric and esophageal cancers in a phase $I$ unit
}

\author{
Denis L. Fontes Jardim¹, Debora de Melo Gagliato ${ }^{1}$, Gerald S. Falchook ${ }^{1}$, Filip \\ Janku ${ }^{1}$, Ralph Zinner ${ }^{1}$, Jennifer J. Wheler ${ }^{1}$, Vivek Subbiah ${ }^{1}$, Sarina A. Piha-Paul ${ }^{1}$, \\ Siqing Fu' ${ }^{1}$, Mariela Blum Murphy ${ }^{2}$, Jaffer Ajani ${ }^{2}$, Chad Tang ${ }^{3}$, Kenneth Hess ${ }^{4}$, \\ Stanley R. Hamilton ${ }^{4}$, Sinchita Roy-Chowdhuri ${ }^{4}$, Razelle Kurzrock ${ }^{5}$, Funda Meric- \\ Bernstam $^{1}$, David S. Hong ${ }^{1}$ \\ ${ }^{1}$ Department of Investigational Cancer Therapeutics (Phase I Clinical Trials Program), The University of Texas MD Anderson \\ Cancer Center, Houston, USA \\ ${ }^{2}$ Department of Gastrointestinal Medical Oncology, The University of Texas MD Anderson Cancer Center, Houston, USA \\ ${ }^{3}$ Department of Radiation Oncology, The University of Texas MD Anderson Cancer Center, Houston, USA \\ ${ }^{3}$ Department of Biostatistics, The University of Texas MD Anderson Cancer Center, Houston, USA \\ ${ }^{4}$ Department of Pathology and Laboratory Medicine, The University of Texas MD Anderson Cancer Center, Houston, USA \\ ${ }^{5}$ Department of Medicine, University of California, San Diego, USA \\ Correspondence to: David S. Hong, email: dshong@mdanderson.org
}

Keywords: MET mutation, MET amplification, esophageal cancer, gastric cancer, C-MET inhibitor

Received: January 28, $2014 \quad$ Accepted: March 14, 2014 Published: March 16, 2014

This is an open-access article distributed under the terms of the Creative Commons Attribution License, which permits unrestricted use, distribution, and reproduction in any medium, provided the original author and source are credited.

\section{ABSTRACT:}

We sought to investigate the demographics and tumor-associated features in patients with gastroesophageal (GE) malignancies referred to our Phase I Program who had formalin-fixed, paraffin-embedded tissue from archival or new biopsies tested for MET mutation and/or amplification. MET amplification was found in 5 of $76(6.6 \%)$ patients $(3 / 34$ [8.8\%] esophageal, $2 / 26[7.7 \%]$ gastric and none in 22 gastroesophageal junction cancers). The only MET mutation detected in 3 of $41(7.3 \%)$ patients was N375S. No demographic and histologic characteristics were associated with specific MET abnormalities. Median overall survival was 3 and 5 months for patients with and without a MET alteration, respectively (hazard ratio $[H R]=2.1$; $95 \% \mathrm{CI}, 0.8$ to $5.5 ; \mathrm{P}=.14)$. Sixteen of $81(20 \%)$ patients were enrolled in a C-MET inhibitor trial. Best responses were stable disease in 3 patients (19\%), including a patient with esophageal adenocarcinoma that remained on the trial for $\mathbf{9 . 9}$ months (wild-type for MET abnormality). All tumors with MET abnormality $(n=3)$ progressed on a C-MET inhibitor in fewer than 2 months. In conclusion, MET abnormalities can be found in a small group of patients with GE adenocarcinoma and further studies are necessary to better characterize the prognostic and predictive impact of MET alterations.

\section{INTRODUCTION}

Cancers of the upper digestive system are a global burden.[1] The prognosis of individuals with advanced esophageal, gastroesophageal junction (GEJ) and gastric cancer is poor[2, 3], and the development of new treatment strategies is an unmeet need. The approval of trastuzumab based on an overall survival benefit in a pre- selected patient population harboring overexpression of HER-2, is a recent advance in the treatment of gastric and gastroesophageal (GE) cancer.[4] Genomic sequencing of these tumors suggests that exploring molecular aberrations in selected patients may offer new avenues for targeted therapeutic opportunities.[5, 6].

MET-positive GE cancer is a promising molecular subtype, particularly as a potential target for c-MET inhibitors. MET encodes a tyrosine kinase receptor 
whose activation is involved in cancer progression. [7, 8] c-MET is physiologically activated by its natural ligand, hepatocyte growth factor (HGF)[9]. Paracrine HGFinduced activation of c-MET plays in important role in the pathogenesis of gastric cancers.[10] Moreover, MET gene amplification is one of the well-recognized mechanisms of c-MET overexpression and constitutive activation of MET/ HGF pathway [11], and has been reported in $2 \%$ to $10 \%$ of GE adenocarcinomas.[12,13] The results of the same studies showed that MET positivity is an independent factor for poor survival regardless of disease stage. In agreement with this observation, $M E T$ amplified tumors display a higher pathologic grade and present at a more advanced stage.[12] Taken together, this data suggest that c-MET is an important target in GE cancers.

Although far less frequent, MET mutations have also been described as a mechanism for c-MET pathway activation in gastric cancer and in other malignancies. $[14,15]$ The recognition of this subset of GE cancer with its poor prognosis is important for referring affected patients to clinical trials with experimental therapies. Many c-MET inhibitors are currently in development and some of them showed activity for GE tumors.[16] In a recent case series, two out of four patients with METamplified GEJ cancers had some tumor shrinkage with crizotinib, a c-MET inhibitor.[12] Rilotumumab is a humanized monoclonal antibody against HGF, and, thus, can interfere with the interaction of HGF and c-MET preventing receptor activation. Early results with this drug in GE cancer showed prolonged survival for patients with high c-MET expression[17] leading to a phase III trial, which is currently accruing patients (NCT01697072). Similar results were obtained with onartuzumab, another monoclonal antibody blocking the c-MET pathway, and an ongoing phase III trial is enrolling a pre-selected patient population with high levels of c-MET expression (NCT01662869).

A way to better characterize MET genetic abnormalities in patients with advanced GE tumors is sorely needed, especially considering the wide availability of different c-MET inhibitors being assessed in clinical protocols. We sought to investigate the demographics and tumor-associated features in consecutive patients with GE malignancies referred to our Phase I Clinical Trials Program who had $M E T$ amplification/mutation testing. We also assessed the outcomes of patients with GE cancer who were included in protocols containing a c-MET inhibitor.

\section{RESULTS}

\section{Patient characteristics}

A total of 81 patients with advanced esophageal $(\mathrm{n}=36)$, GEJ $(\mathrm{n}=17)$ or gastric $(\mathrm{n}=28)$ cancers were evaluated for $M E T$ mutation/variant (41 patients) or amplification (76 patients). Thirty-six patients were tested simultaneously for both genetic abnormalities. Except for two patients with a neuroendocrine histology and one with squamous cell cancer, all remaining patients had adenocarcinoma. Median age at diagnosis was 56 years (range, 27-88 years). The median number of prior therapies was 2 (range, 0-5). Patient characteristics according to $M E T$ status are summarized in Table 1.

\section{$M E T$ genetic aberrations}

Five out of $76(6.6 \%)$ patients had a MET gene amplification in FISH analysis (3 esophageal and 2 gastric cancers, all adenocarcinomas). The copy number of the MET gene in relation to CEP7 ranged from 3.11 to 16.4. A $M E T$ mutation/variant was detected in 3 out of 41 patients (7.3\%). Of these patients, two had gastric and one had esophageal cancer. All mutations/variants detected were N375S, which has been previously reported as a polymorphism[18] (Table 2). MET amplification and mutation were mutually exclusive in patients simultaneously tested for both aberrations $(n=36)$. The prevalence of $M E T$ mutation/variant and amplification was similar regardless what site of disease was tested (MET mutation, $7 \%$ vs. $9 \%$; MET amplification, $8 \%$ vs. $6 \%$, for primary vs. metastatic tissue, respectively)

\section{Comparison of clinical and mutational characteristics}

No meaningful differences were detected in the age of diagnosis or number and pattern of metastatic sites among patients with $M E T$ mutation/amplification and wild-type patients (Table 1). There was a higher proportion of female and Asian individuals among patients testing positive for a $M E T$ variant ( 2 out of 3, 67\%) although the numbers are too small for definitive conclusions to be drawn. The proportion of poorly differentiated tumors was similar in MET positive patients compared to wild-type as well ( 1 out of 3 for $M E T$ mutated versus 22 out of 38 for nonmutated and 3 out of 5 for $M E T$ amplified versus 37 out of 71 for patients with non-amplified MET). Few concomitant mutations were observed in the $M E T$ positive population: one patient with a $M E T$ variant and one with MET amplification had a concomitant TP53 mutation, while $M E T$ and HER-2 amplification were simultaneously detected in one patient (Table 2).

\section{Analysis of survival of $M E T$ positive patients and outcomes on Phase I protocols}

Patients positive for either MET mutation/variant or MET amplification (MET positive group, $\mathrm{n}=8$ ) were 
Table 1: Demographic, histologic and genetic characteristics of patients stratified by c-MET mutation and amplification status

\begin{tabular}{|c|c|c|c|c|}
\hline Characteristic & \begin{tabular}{|l|}
$\begin{array}{l}\text { Not mutated } \\
(\mathrm{n}=38)(\%)\end{array}$ \\
\end{tabular} & \begin{tabular}{|l|} 
Mutated \\
$(\mathrm{n}=3)(\%)$
\end{tabular} & \begin{tabular}{|l|}
$\begin{array}{l}\text { Not amplified } \\
(\mathrm{n}=71)(\%)\end{array}$ \\
\end{tabular} & \begin{tabular}{|l}
$\begin{array}{l}\text { Amplified }(\mathrm{n}=5) \\
(\%)\end{array}$ \\
\end{tabular} \\
\hline Age At Diagnosis: Median (IQR) & $51(34-87)$ & $48(27-67)$ & $56(27-87)$ & $60(34-70)$ \\
\hline Prior Therapies: Median (IQR) & $2(0-5)$ & $2(2)$ & $2(0-5)$ & $2(1-4)$ \\
\hline \multicolumn{5}{|l|}{ Gender } \\
\hline Male & $27(71)$ & $1(33)$ & $58(82)$ & $4(80)$ \\
\hline Female & $11(29)$ & $2(67)$ & $13(18)$ & $1(20)$ \\
\hline \multicolumn{5}{|l|}{ Ethnicity (\%) } \\
\hline Asian/Arabic & $5(13)$ & $2(67)$ & $9(13)$ & $1(20)$ \\
\hline Black & 0 & 0 & 0 & 0 \\
\hline Hispanic & $5(13)$ & \begin{tabular}{|l|l|}
0 \\
\end{tabular} & $10(14)$ & \begin{tabular}{|l|l|}
0 \\
\end{tabular} \\
\hline White & $27(71)$ & $1(33)$ & $51(72)$ & $4(80)$ \\
\hline Undefined & $1(3)$ & 0 & $1(1)$ & 0 \\
\hline \multicolumn{5}{|l|}{ Diagnosis (\%) } \\
\hline Esophageal & $13(34)$ & $1(33)$ & $31(44)$ & $3(60)$ \\
\hline GEJ & $8(21)$ & 0 & $16(22)$ & 0 \\
\hline Gastric & $17(45)$ & $2(67)$ & $24(34)$ & $2(40)$ \\
\hline \multicolumn{5}{|l|}{ Histology (\%) } \\
\hline Adenocarcinoma & $38(100)$ & $3(100)$ & $68(96)$ & $5(100)$ \\
\hline Intestinal & 3 & 1 & 2 & 2 \\
\hline Diffuse & 10 & 1 & 16 & 1 \\
\hline Not classified & 25 & 1 & 50 & 2 \\
\hline Squamous Cell & 0 & 0 & $1(1)$ & 0 \\
\hline Neuroendocrine & 0 & 0 & $2(3)$ & 0 \\
\hline \multicolumn{5}{|l|}{ Grade } \\
\hline Well differentiated & 0 & $\overline{0}$ & 0 & 0 \\
\hline Moderately differentiated & $15(39)$ & $2(67)$ & $32(45)$ & $2(40)$ \\
\hline Poorly differentiated & $22(58)$ & $1(33)$ & $37(52)$ & $3(60)$ \\
\hline Not evaluated & $1(3)$ & \begin{tabular}{|l|l|}
0 \\
\end{tabular} & $2(3)$ & \begin{tabular}{|l|l|}
0 \\
\end{tabular} \\
\hline \multicolumn{5}{|l|}{ Metastasis (\%) } \\
\hline \# Met Sites - median (range) & $2(1-5)$ & $2(1-3)$ & $3(1-6)$ & $2(2-5)$ \\
\hline Liver & $18(47)$ & $2(67)$ & $39(55)$ & $3(60)$ \\
\hline Lungs & $12(32)$ & 0 & $12(17)$ & $2(40)$ \\
\hline Bone & $8(21)$ & 0 & $13(18)$ & $1(20)$ \\
\hline CNS & $3(8)$ & 0 & $4(6)$ & 0 \\
\hline Peritoneum & $19(50)$ & $2(67)$ & $31(44)$ & $2(40)$ \\
\hline Lymph nodes & $24(63)$ & $2(67)$ & $46(65)$ & $4(80)$ \\
\hline \multicolumn{5}{|l|}{ Tissue of analysis } \\
\hline Primary & $28(74)$ & $2(67)$ & $24(34)$ & $2(40)$ \\
\hline Metastasis & $10(26)$ & $1(33)$ & $47(66)$ & $3(60)$ \\
\hline \multicolumn{5}{|l|}{ Concomitant aberrations (\%) } \\
\hline Her-2 positivity & $5 / 37$ & $0 / 3$ & $8 / 60$ & $1 / 4$ \\
\hline PIK3CA & $3 / 36$ & $0 / 3$ & $5 / 54$ & $0 / 4$ \\
\hline KRAS & $0 / 32$ & $0 / 3$ & $2 / 44$ & $0 / 3$ \\
\hline EGFR & $1 / 31$ & $0 / 2$ & $1 / 36$ & $0 / 3$ \\
\hline P53 & $8 / 20$ & \begin{tabular}{|l|}
$1 / 1$ \\
\end{tabular} & $8 / 16$ & $1 / 3$ \\
\hline BRAF & $1 / 32$ & $0 / 3$ & $0 / 38$ & $0 / 3$ \\
\hline NRAS & $0 / 30$ & $0 / 1$ & $0 / 26$ & $0 / 3$ \\
\hline PTEN loss & $2 / 21$ & $0 / 2$ & $3 / 39$ & $0 / 1$ \\
\hline
\end{tabular}


Table 2: Histology and mutation status of patients with MET mutation and amplification, and their response to c-MET inhibitors

\begin{tabular}{|l|l|l|l|l|l|}
\hline Patient No. & Diagnosis & $\begin{array}{l}\text { Mutation/ } \\
\text { Copy Number }\end{array}$ & $\begin{array}{l}\text { Concomitant } \\
\text { Abnormalities }\end{array}$ & Best Response & PFS (mos) \\
\hline Met mutated & \multicolumn{5}{|l|}{} \\
\hline 1 & Esophageal & N375S & TP53 & - & - \\
\hline 2 & Gastric & N375S & - & - & - \\
\hline 3 & Gastric & N375S & - & PD & 1 \\
\hline Met amplified & Gastric & 4.2 & TP53 & PD & 1.5 \\
\hline 4 & Esophageal & 16.14 & Her-2 overexp & - & - \\
\hline 5 & Gastric & 12 & - & - & \\
\hline 6 & Esophageal & 3.11 & - & PD & 1 \\
\hline 7 & Esophageal & 9.23 & - & - & \\
\hline 8 &
\end{tabular}

compared with patients wild-type for both abnormalities (MET negative group, $\mathrm{n}=30$ ). Median OS from Phase I consult was 3 months versus 5 months for the $M E T$ positive and negative groups, respectively (HR for death $=2.1,95 \% \mathrm{CI}, 0.8$ to $5.5, \mathrm{p}=0.14$; Figure 1 ).

Of the 81 patients included in this analysis, 44 $(54 \%)$ were treated on at least one Phase I protocol. This proportion was $37.5 \%$ (3 out of 8 ) for MET positive patients and 56\% (41 out of 73) for MET negative patients. Of note, the three patients with a $M E T$ abnormality were treated on a Phase I protocol containing a c-MET inhibitor. These patients had a PFS on these protocols of 1.0, 1.0 and 1.5 months (Table 2). Median PFS for the MET negative population on their first Phase I treatment regimen was 1.8 months (range, 0.26 to 9.9 months). Sixteen out of the 81 patients included in this study (20\%) were enrolled on a protocol with a c-MET inhibitor. All of the c-MET inhibitors reported here were small-molecule inhibitors of

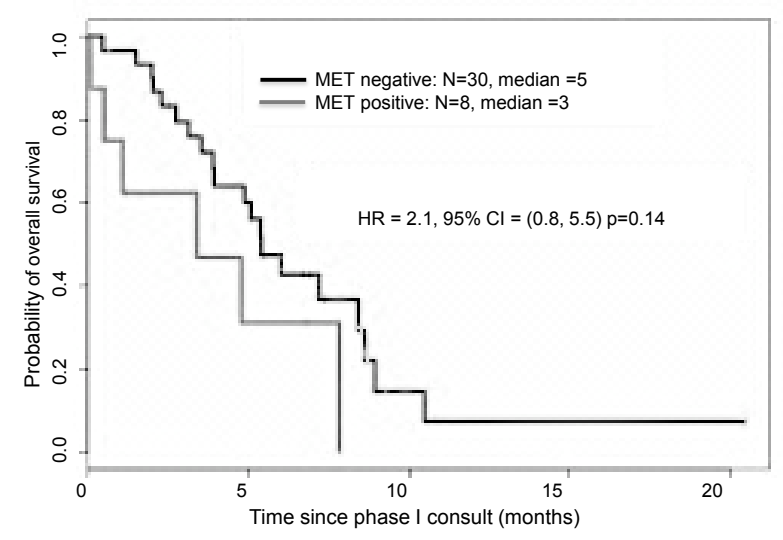

Figure 1: Kaplan-Meier overall survival curves for patients with gastroesophageal tumors according to MET status starting from presentation in a Phase I Clinic the MET receptor tyrosine kinase (11 selective and 5 nonselective). No partial responses were detected and best responses were stable disease in three patients (Figure 2A). Median PFS was 1.4 months (range 0.33 to 9.9 months, Figure 2B) and all three patients with the greatest disease control rate had esophageal adenocarcinoma and were wild-type for a MET abnormality (Table 3).

\section{DISCUSSION}

Here we report MET amplification in 6.6\% (5 out of 76) patients with advanced GE cancers referred to our Phase I department. MET mutation occurred at a similar frequency (7.3\%), but was considered to be germline.[18] Our data are in line with previous series' reporting $M E T$ amplification in $2-7 \%$ of GE adenocarcinomas. $[12,19,20]$ Although we included only one patient with a squamous histology, the prevalence of MET amplification in this histology is reported to be as low as $1 \%$.[21]

The prevalence of MET amplification in GE cancer increased up to $5 \%$ with higher grade and more advanced disease in a previous report.[12] Considering that our population consisted mostly of patients with refractory and advanced disease, it is plausible to expect a higher prevalence of $M E T$ amplification compared to previous reports. However, we could not demonstrate any significant demographic and/or tumor associated features of $M E T$ positive tumors, including poor differentiation and an aggressive histology, as was previously reported for GE tumors and other malignancies. $[12,15]$ Selection bias is a possible explanation for this discrepancy, as patients referred to a Phase I unit generally have a reasonable performance status. Consequently, patients with a very aggressive phenotype may have been unwittingly excluded.

As expected, we detected a trend for a worse OS for MET positive GE cancers. Although this difference was not statistically significant, the small number of 
Table 3: Histology and mutation status and response of patients treated with c-MET inhibitors

\begin{tabular}{|c|c|c|c|c|c|}
\hline $\begin{array}{l}\text { Patient } \\
\text { No. }\end{array}$ & Histology & $\begin{array}{l}\text { CMET } \\
\text { abnormality }\end{array}$ & $\begin{array}{l}\text { Other } \\
\text { Mutations }\end{array}$ & Best Response & PFS (mos) \\
\hline 1 & Esophageal & - & - & SD & 4.0 \\
\hline 2 & Esophageal & - & - & SD & 4.2 \\
\hline 3 & Esophageal & - & - & SD & 9.9 \\
\hline 4 & Esophageal & - & Her2 ampl & $\mathrm{PD}$ & 1.4 \\
\hline 5 & Esophageal & - & - & $\mathrm{PD}$ & 1.4 \\
\hline 6 & Esophageal & - & - & $\mathrm{PD}$ & 1.4 \\
\hline 7 & Esophageal & - & - & $\mathrm{PD}$ & 1.1 \\
\hline 8 & Esophageal & - & - & $\mathrm{PD}$ & 0.3 \\
\hline 9 & Esophageal & - & $\begin{array}{l}\text { PTEN loss, } \\
\text { TP53 }\end{array}$ & PD & 2.1 \\
\hline 10 & Esophageal & Amplification & \begin{tabular}{|l|}
- \\
\end{tabular} & $\mathrm{PD}$ & 1.0 \\
\hline 11 & Gastric & Amplification & TP53 & $\mathrm{PD}$ & 1.5 \\
\hline 12 & Gastric & $\begin{array}{l}\text { Variant } \\
(\mathrm{N} 375 \mathrm{~S})\end{array}$ & - & PD & 1.0 \\
\hline 13 & Gastric & - & $\begin{array}{l}\text { PTEN loss, } \\
\text { BRAF }\end{array}$ & PD & 2.9 \\
\hline 14 & Gastric & - & \begin{tabular}{|l|}
- \\
\end{tabular} & $\mathrm{PD}$ & 1.4 \\
\hline 15 & Gastric & - & - & $\mathrm{PD}$ & 1.4 \\
\hline 16 & Gastroesophageal & - & $\begin{array}{l}\text { Her } 2 \text { ampl } \\
\text { TP53 }\end{array}$ & PD & 0.6 \\
\hline
\end{tabular}

patients in this cohort may contribute to the lack of statistical power. We previously detected similar findings for patients with ovarian[22] and genitourinary cancers (submitted), suggesting that the aggressive phenotype conferred by MET genetic abnormalities is not dependent on tissue origin. In agreement with our results, patients with esophageal cancer and high c-MET expression had significantly reduced $\mathrm{OS}$ and disease-free survival in another series.[13] The OS of patients with advanced $M E T$-amplified GE cancers was previously reported as 7.1 months[12]. Of note, in the cohort of patients in this study length of survival was assessed from the time of initial diagnosis. To avoid biased selection, we computed survival from the time of initial Phase I consultation and found an OS rate of 3 months. Considering that most patients had received several prior therapies (median of $2)$, this is an acceptable result.

It is somewhat challenging to enroll patients with relatively rare molecular abnormalities that are associated with a poor prognosis on clinical trials. Out of eight patients with $M E T$ abnormalities in our study, only three were included in trials with c-MET inhibitors. Other authors reported an even worse accrual. Notably, of 10 patients with $M E T$-amplified GE cancers, none were included in a crizotinib trial.[12] Preclinical data suggest that MET amplified gastric tumors may be sensitive to c-MET inhibitors.[23] We report disappointing results for the three patients with $M E T$ abnormalities included in trials with these agents ( 1 patient with a $M E T$ variant and 2 with $M E T$ amplification). None of them had a response and their tumors invariably progressed in fewer than 2 months after starting treatment with a c-MET inhibitor. Similar findings were reported for two patients with $M E T$-amplified gastric cancers treated with foretinib, a non-selective c-MET inhibitor.[24] Both were found to have progressive disease at the time of their first restaging assessment. Lennerz et al. reported that two out of four patients with $M E T$-amplified GE tumors had rapid disease progression when treated with crizotinib. The other two patients had tumor reduction (up to $39 \%$ ), although it did not last more than 4 months. Of note, responding patients had a $M E T / C E P 7$ ratio of more than 5 and both of our $M E T$-amplified patients treated with a c-MET inhibitor had a ratio inferior to this. Interestingly, a recent series showed that the level of HER-2 amplification predicted sensitivity to trastuzumab.[25] In this study, a ratio of 4.7 was discriminative of sensitive patients, which suggests that a similar relation can be explored for $M E T$ amplification and sensitivity to c-MET inhibitors.

Additionally, one of the patients receiving a c-MET inhibitor in our series had a N375S MET variant. As demonstrated in preclinical models, this variant may confer resistance to c-MET inhibitors.[18] Clinical data suggested that this variant might decrease the risk of gastric cancer, probably through reduced affinity of HGF to the c-MET receptor.[26] Although similar prognostic 
implication was not confirmed in lung cancer, decreased cell death upon treatment with a c-MET inhibitor was showed in the presence of N375S variant.[27] In the light of our findings, the correlation of this variant and response to c-MET targeted agents is worth of further investigation.

Among all patients treated on trials with c-MET inhibitors in our series, the best result was stable disease for almost 10 months in a patient with esophageal adenocarcinoma who had received 3 prior therapies. Of note, this patient was negative for $M E T$ mutation and amplification, as well for other mutations tested (HER2, TP53, PIK3CA, PTEN, BRAF, c-KIT, ALK). Interestingly, encouraging preliminary results for treatment with onartuzumab and rilotumumab, which are antibodies against hepatocyte growth factor, were reported for GEJ and gastric cancers with a high expression of c-MET in immunohistochemical analysis[28], leading to two Phase III trials that are currently open for accrual. Taken together, these data suggest that further studies exploring different MET biomarkers simultaneously, such as via
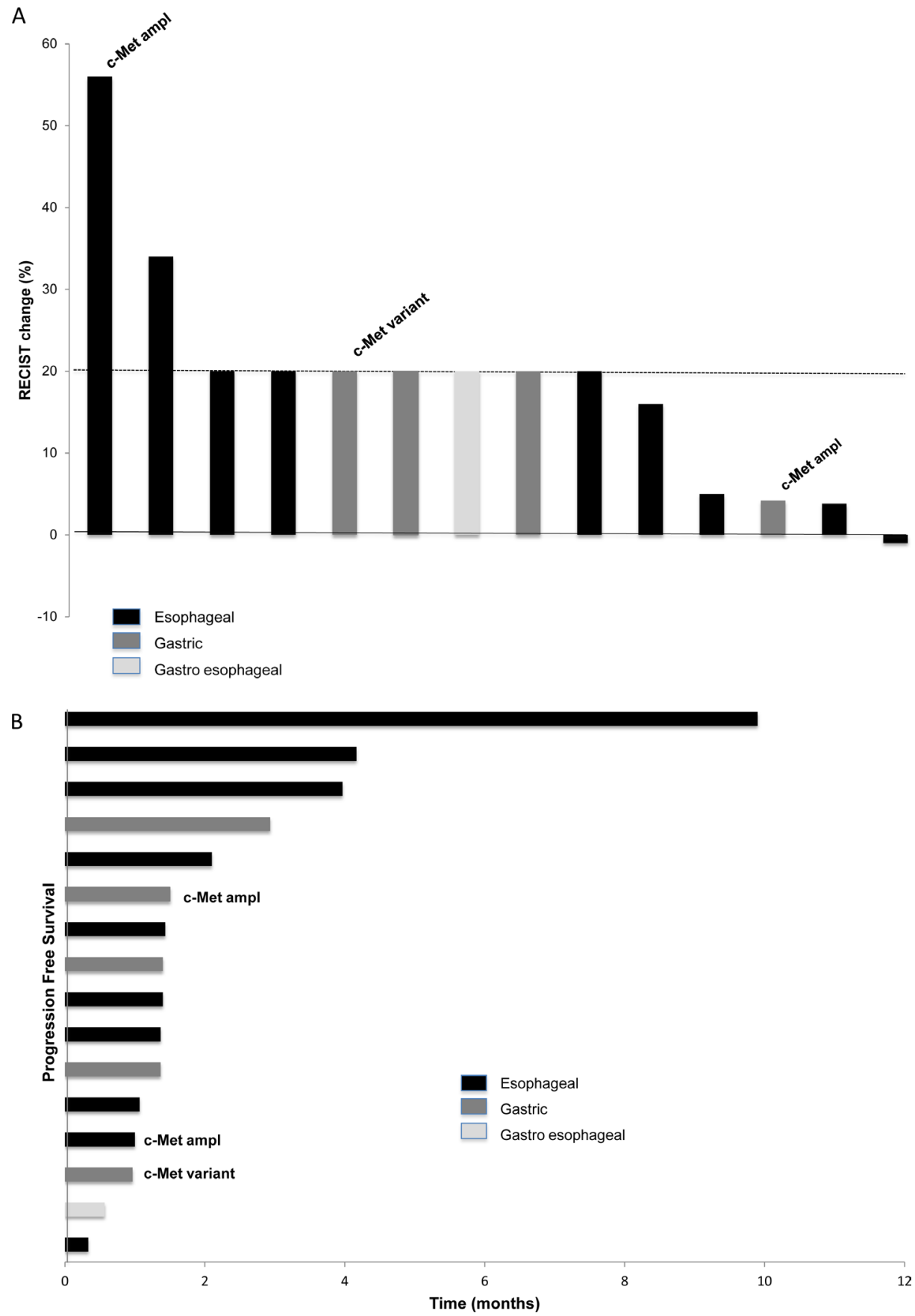

Figure 2: Waterfall plot showing responses (A) and PFS (B) of patients with gastroesophageal tumors treated on a phase I protocol including a c-MET inhibitor. Patients harboring a MET genetic abnormality are indicated 
genetic and immunohistochemical analysis, is necessary to better understand predictive factors for response to c-MET inhibitors.

One of the weaknesses of this work is the lack of analysis of c-MET receptor expression levels, limiting some of our comparisons with previous studies correlating receptor overexpression with clinical and pathological features of GE cancers.[29, 30] The small numbers of patients harboring MET abnormalities in our series is another intrinsic limitation and precludes drawing definitive conclusions. Nonetheless, our results add to the current body of knowledge correlating the presence of $M E T$ genetic abnormalities with aggressive behavior and a worse prognosis in GE cancers. It is not clear if c-MET inhibition will offer reasonable antitumor activity for this population, but further exploration of biomarkers will likely clarify this issue.

\section{PATIENTS AND METHODS}

\section{Patients}

We retrospectively reviewed the electronic medical records of consecutive patients with advanced esophageal, GEJ and gastric carcinoma referred to the Department of Investigational Cancer Therapeutics at The University of Texas MD Anderson Cancer Center (MD Anderson) starting in May 2010 until March 2013. Patients were eligible for inclusion in data analysis if a primary diagnosis of any of these malignancies was confirmed and a tumor sample was sent to evaluate MET mutation or amplification status. This study and all associated treatments were conducted in accordance with the guidelines of the MD Anderson Institutional Review Board.

\section{Tissue samples and molecular analysis}

MET mutation/variant and amplification were investigated in archival formalin-fixed, paraffinembedded tissue blocks or material from fine needle aspiration biopsies obtained from diagnostic and/or therapeutic procedures. All histology was centrally reviewed at MD Anderson. MET mutation or variant analysis was performed in different Clinical Laboratory Improvement Amendment-certified laboratories as part of a gene panel analysis or in a single test. This included assessment of 182 genes using a targeted next-generation sequencing Foundation One platform (Foundation Medicine, Cambridge, MA), 46 genes in an Ion Torrent next-generation sequencing procedure (Baylor's Cancer Genetics Laboratory, Houston, TX) and 53 genes using a Sequenom Mass ARRAY platform (Knight Diagnostics, Portland, OR) or a PCR-based primer extension assay assessing mutational hot spots in the $M E T$ gene in the Division of Pathology and Laboratory Medicine at MD Anderson.

$M E T$ amplification was analyzed via fluorescence in situ hybridization (FISH) at MD Anderson or Baylor`s Cancer Genetic Laboratory. Copy numbers were expressed as gene copy number in relation to $C E P 7$, a gene located near the centrosome of the same chromosome. MET was considered amplified when the MET/CEP7 signal ratio was $\geq 2.0$ or when this ratio was $<2.0$ but there were $>$ 20 copies of MET signals and/or clusters in $>10 \%$ of the tumor nuclei counted.

\section{Treatment and evaluation}

Patients referred to the Phase I Clinic who MET inclusion criteria were enrolled in clinical trials judged to be clinically appropriate by attending physicians. Treatment continued until disease progression, withdrawal of consent by the patient, clinical judgment deeming the necessity of removing a patient from a clinical trial, or development of unacceptable toxicity or death. Clinical assessments were performed as specified in each protocol, typically before the initiation of therapy and then at a minimum at the beginning of each new treatment cycle. Treatment response was assessed using computed tomography scans, magnetic resonance imaging and/or positron emission tomography scans at baseline before treatment initiation and then every 2 cycles (6-8 weeks). All radiographs were read in the Department of Radiology at MD Anderson and were reviewed in the Department of Investigational Cancer Therapeutics tumor measurement clinic. Responses were categorized using RECIST on the basis of specific protocol requirements[31, 32] and were reported as best response.

\section{Statistical analysis}

Patient characteristics including demographics, tumor type, $M E T$ mutation and/or amplification status and associated genetic abnormalities were summarized using frequency distributions and percentages. Progressionfree survival (PFS) was defined as the interval from the start of therapy to treatment discontinuation for disease progression or death related to disease progression. Overall survival (OS) was assessed using KaplanMeier curve analysis starting from the date of the first appointment in the Phase I Clinic.

\section{ACKNOWLEDGMENTS:}

The authors acknowledge Joann Aaron, MA, in the Department of Investigational Cancer Therapeutics for editorial support. Dr Hess would like to acknowledge his support funding (MDACC CCSG (P30 CA016672)). 


\section{Disclosure:}

David S. Hong received research support from Amgen and Dr. Gerald Falchook research funding, travel reimbursement, and honoraria from EMD Serono. All remaining authors have declared no conflicts of interest.

\section{Funding:}

This work was supported in part by the Sheikh Khalifa Al Nahyan Ben Zayed Institute of Personalized Cancer Therapy, NCATS grant UL1 TR000371

\section{REFERENCES}

1. Ajani JA. Gastroesophageal cancers: progress and problems. Journal of the National Comprehensive Cancer Network : JNCCN. 2008; 6(9):813-814.

2. Hartgrink HH, Jansen EP, van Grieken NC and van de Velde CJ. Gastric cancer. Lancet. 2009; 374(9688):477490.

3. National Cancer Institute. Surveillance Epidemiology and End Results.

4. Bang YJ, Van Cutsem E, Feyereislova A, Chung HC, Shen L, Sawaki A, Lordick F, Ohtsu A, Omuro Y, Satoh T, Aprile G, Kulikov E, Hill J, Lehle M, Ruschoff J, Kang YK, et al. Trastuzumab in combination with chemotherapy versus chemotherapy alone for treatment of HER2-positive advanced gastric or gastro-oesophageal junction cancer (ToGA): a phase 3, open-label, randomised controlled trial. Lancet. 2010; 376(9742):687-697.

5. Dulak AM, Schumacher SE, van Lieshout J, Imamura Y, Fox C, Shim B, Ramos AH, Saksena G, Baca SC, Baselga J, Tabernero J, Barretina J, Enzinger PC, Corso G, Roviello $\mathrm{F}$, Lin L, et al. Gastrointestinal adenocarcinomas of the esophagus, stomach, and colon exhibit distinct patterns of genome instability and oncogenesis. Cancer research. 2012; 72(17):4383-4393.

6. Agrawal N, Jiao Y, Bettegowda C, Hutfless SM, Wang Y, David S, Cheng Y, Twaddell WS, Latt NL, Shin EJ, Wang LD, Wang L, Yang W, Velculescu VE, Vogelstein B, Papadopoulos N, et al. Comparative genomic analysis of esophageal adenocarcinoma and squamous cell carcinoma. Cancer discovery. 2012; 2(10):899-905.

7. Paliouras GN, Naujokas MA and Park M. Pak4, a novel Gab1 binding partner, modulates cell migration and invasion by the Met receptor. Molecular and cellular biology. 2009; 29(11):3018-3032.

8. Gherardi E, Birchmeier W, Birchmeier C and Vande Woude G. Targeting MET in cancer: rationale and progress. Nature reviews Cancer. 2012; 12(2):89-103.

9. Bottaro DP, Rubin JS, Faletto DL, Chan AM, Kmiecik TE, Vande Woude GF and Aaronson SA. Identification of the hepatocyte growth factor receptor as the c-met protooncogene product. Science. 1991; 251(4995):802-804.

10. Zhao L, Yasumoto K, Kawashima A, Nakagawa $T$, Takeuchi S, Yamada T, Matsumoto K, Yonekura K, Yoshie $\mathrm{O}$ and Yano S. Paracrine activation of MET promotes peritoneal carcinomatosis in scirrhous gastric cancer. Cancer science. 2013; 104(12):1640-1646.

11. Comoglio PM, Giordano S and Trusolino L. Drug development of MET inhibitors: targeting oncogene addiction and expedience. Nature reviews Drug discovery. 2008; 7(6):504-516.

12. Lennerz JK, Kwak EL, Ackerman A, Michael M, Fox SB, Bergethon K, Lauwers GY, Christensen JG, Wilner KD, Haber DA, Salgia R, Bang YJ, Clark JW, Solomon BJ and Iafrate AJ. MET amplification identifies a small and aggressive subgroup of esophagogastric adenocarcinoma with evidence of responsiveness to crizotinib. Journal of clinical oncology : official journal of the American Society of Clinical Oncology. 2011; 29(36):4803-4810.

13. Tuynman JB, Lagarde SM, Ten Kate FJ, Richel DJ and van Lanschot JJ. Met expression is an independent prognostic risk factor in patients with oesophageal adenocarcinoma. British journal of cancer. 2008; 98(6):1102-1108.

14. Lee JH, Han SU, Cho H, Jennings B, Gerrard B, Dean M, Schmidt L, Zbar B and Vande Woude GF. A novel germ line juxtamembrane Met mutation in human gastric cancer. Oncogene. 2000; 19(43):4947-4953.

15. Blumenschein GR, Jr., Mills GB and Gonzalez-Angulo AM. Targeting the hepatocyte growth factor-cMET axis in cancer therapy. Journal of clinical oncology : official journal of the American Society of Clinical Oncology. 2012; 30(26):3287-3296.

16. Forde PM and Kelly RJ. Genomic alterations in advanced esophageal cancer may lead to subtype-specific therapies. The oncologist. 2013; 18(7):823-832.

17. Oliner KS, Tang R, Anderson A, Lan Y, Iveson $\mathrm{T}$, Donehower RC, Jiang Y, Dubey S and Loh E. Evaluation of MET pathway biomarkers in a phase II study of rilotumumab (R, AMG 102) or placebo (P) in combination with epirubicin, cisplatin, and capecitabine (ECX) in patients (pts) with locally advanced or metastatic gastric $(\mathrm{G})$ or esophagogastric junction (EGJ) cancer. ASCO Meeting Abstracts. 2012; 30(15_suppl):4005.

18. Krishnaswamy S, Kanteti R, Duke-Cohan JS, Loganathan S, Liu W, Ma PC, Sattler M, Singleton PA, Ramnath N, Innocenti F, Nicolae DL, Ouyang Z, Liang J, Minna J, Kozloff MF, Ferguson MK, et al. Ethnic differences and functional analysis of MET mutations in lung cancer. Clinical cancer research : an official journal of the American Association for Cancer Research. 2009; 15(18):5714-5723.

19. Hara T, Ooi A, Kobayashi M, Mai M, Yanagihara K and Nakanishi I. Amplification of c-myc, K-sam, and c-met in gastric cancers: detection by fluorescence in situ hybridization. Laboratory investigation; a journal of technical methods and pathology. 1998; 78(9):1143-1153. 
20. Houldsworth J, Cordon-Cardo C, Ladanyi M, Kelsen DP and Chaganti RS. Gene amplification in gastric and esophageal adenocarcinomas. Cancer research. 1990; 50(19):6417-6422.

21. Kato H, Arao T, Matsumoto K, Fujita Y, Kimura H, Hayashi H, Nishiki K, Iwama M, Shiraishi O, Yasuda A, Shinkai M, Imano M, Imamoto H, Yasuda T, Okuno K, Shiozaki H, et al. Gene amplification of EGFR, HER2, FGFR2 and MET in esophageal squamous cell carcinoma. International journal of oncology. 2013; 42(4):1151-1158.

22. Tang C, Jardim DL, Falchook GS, Hess K, Fu S, Wheler JJ, Zinner RG, Naing A, Tsimberidou AM, de Melo Gagliato D, Westin SN, Meric-Bernstam F, Kurzrock R and Hong DS. MET nucleotide variations and amplification in advanced ovarian cancer: characteristics and outcomes with c-Met inhibitors. Oncoscience. 2013; in press.

23. Okamoto W, Okamoto I, Arao T, Kuwata K, Hatashita E, Yamaguchi H, Sakai K, Yanagihara K, Nishio K and Nakagawa K. Antitumor action of the MET tyrosine kinase inhibitor crizotinib (PF-02341066) in gastric cancer positive for MET amplification. Molecular cancer therapeutics. 2012; 11(7):1557-1564.

24. Shah MA, Wainberg ZA, Catenacci DV, Hochster HS, Ford J, Kunz P, Lee FC, Kallender H, Cecchi F, Rabe DC, Keer H, Martin AM, Liu Y, Gagnon R, Bonate P, Liu L, et al. Phase II study evaluating 2 dosing schedules of oral foretinib (GSK1363089), cMET/VEGFR2 inhibitor, in patients with metastatic gastric cancer. PloS one. 2013; 8(3):e54014.

25. Gomez-Martin C, Plaza JC, Pazo-Cid R, Salud A, Pons F, Fonseca P, Leon A, Alsina M, Visa L, Rivera F, Galan MC, Del Valle E, Vilardell F, Iglesias M, Fernandez S, Landolfi $\mathrm{S}$, et al. Level of HER2 Gene Amplification Predicts Response and Overall Survival in HER2-Positive Advanced Gastric Cancer Treated With Trastuzumab. Journal of clinical oncology : official journal of the American Society of Clinical Oncology. 2013; 31(35):4445-4452.

26. Liu Y, Zhang Q, Ren C, Ding Y, Jin G, Hu Z, Xu Y and Shen H. A germline variant N375S in MET and gastric cancer susceptibility in a Chinese population. Journal of biomedical research. 2012; 26(5):315-318.

27. Shieh JM, Tang YA, Yang TH, Chen CY, Hsu HS, Tan YH, Salgia R and Wang YC. Lack of association of C-MetN375S sequence variant with lung cancer susceptibility and prognosis. International journal of medical sciences. 2013; 10(8):988-994.

28. Forde PM and Kelly RJ. Genomic Alterations in Advanced Esophageal Cancer May Lead to Subtype-Specific Therapies. The oncologist. 2013.

29. Nakajima M, Sawada H, Yamada Y, Watanabe A, Tatsumi M, Yamashita J, Matsuda M, Sakaguchi T, Hirao T and Nakano H. The prognostic significance of amplification and overexpression of c-met and c-erb B-2 in human gastric carcinomas. Cancer. 1999; 85(9):1894-1902.

30. Drebber U, Baldus SE, Nolden B, Grass G, Bollschweiler
E, Dienes HP, Holscher AH and Monig SP. The overexpression of c-met as a prognostic indicator for gastric carcinoma compared to p53 and p21 nuclear accumulation. Oncology reports. 2008; 19(6):1477-1483.

31. Eisenhauer EA, Therasse P, Bogaerts J, Schwartz LH, Sargent D, Ford R, Dancey J, Arbuck S, Gwyther S, Mooney M, Rubinstein L, Shankar L, Dodd L, Kaplan R, Lacombe D and Verweij J. New response evaluation criteria in solid tumours: revised RECIST guideline (version 1.1). European journal of cancer. 2009; 45(2):228-247.

32. Therasse P, Arbuck SG, Eisenhauer EA, Wanders J, Kaplan RS, Rubinstein L, Verweij J, Van Glabbeke M, van Oosterom AT, Christian MC and Gwyther SG. New guidelines to evaluate the response to treatment in solid tumors. European Organization for Research and Treatment of Cancer, National Cancer Institute of the United States, National Cancer Institute of Canada. Journal of the National Cancer Institute. 2000; 92(3):205-216. 